\section{SUPERIOR DENTINE TUBULE OCCLUSION}

Two in vitro studies provide dental professionals with further evidence of the effectiveness of the PRO-ARGIN technology compared to other technologies on the market.

Colgate SENSITIVE PRO-Relief toothpaste provides superior dentine tubule occlusion when compared with stannous fluoride/sodium fluoride technology (91\% vs. $67 \%)^{1}$ and novamin/sodium fluoride technology ( $88 \%$ vs. $50 \%){ }^{2}$

Recommend Colgate SENSITIVE PRO-Relief toothpaste to your patients to provide superior dentine tubule occlusion ${ }^{1,2}$ [vs novamin/sodium fluoride technology and stannous fluoride/sodium fluoride technology $(\mathrm{p}<0.05)$ ], [In vitro study, actual confocal images after five applications $(\mathrm{p}$ $<0.05$ )], an acid resistant layer, ${ }^{3}$ Instant [for instant relief, apply directly to the sensitive tooth with fingertip and gently massage for one minute] sensitivity pain relief, ${ }^{4}$ long lasting sensitivity pain relief $f^{4}$ and improved patient satisfaction. ${ }^{6,7}$

Visit www.colgateprofessional.co.uk for further information and to watch the superior technology in action.

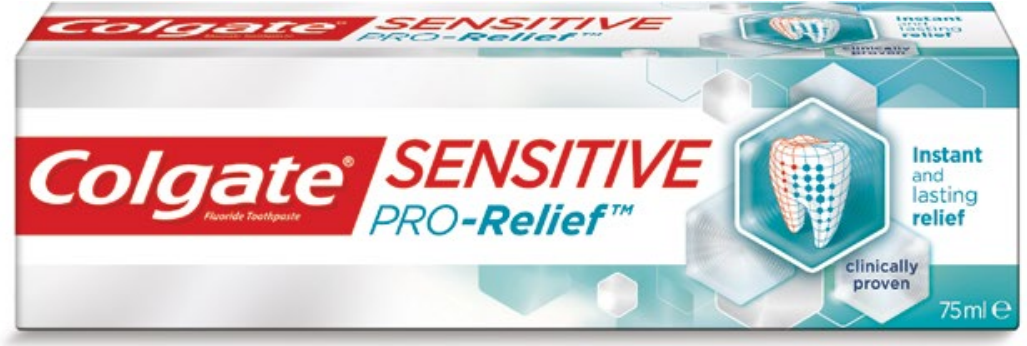

\section{References}

1. Hines D et al. Poster, July 2018 IADR. Colgate-Palmolive Company 2018.

2. Hines D et al. Poster \#0742, March 2018 AADR. Colgate-Palmolive Company 2018.

3. Report Deon Hines-0003, 2016, confocal images after five applications.

4. Nathoo S, Delgado E, Zhang Y P, DeVizio W, Cummins D, Mateo L R. Comparing the efficacy in providing instant relief of dentin hypersensitivity of a new toothpaste containing $8.0 \%$ arginine, calcium carbonate, and 1450 ppm fluoride relative to a benchmark desensitizing toothpaste containing $2 \%$ potassium ion and $1450 \mathrm{ppm}$ fluoride, and to a control toothpaste with 1450 ppm fluoride: a three-day clinical study in New Jersey, USA. J Clin Dent 2009; 20(Spec Iss): 123-130.

5. Docimo R, Montesani L, Maturo P et al. Comparing the efficacy in reducing dentin hypersensitivity of a new toothpaste containing $8.0 \%$ arginine, calcium carbonate, and $1450 \mathrm{ppm}$ fluoride to a commercial sensitive toothpaste containing $2 \%$ potassium ion: an eight-week clinical study in Rome, Italy. J Clin Dent 2009; 20(Spec Iss): 17-22.

6. Ipsos, UK Patient Experience Programme on Colgate Sensitive Pro-ReliefTM, results collected after 2-week trial, 192 respondents, 2016.

7. Gernhardt C R. Poster presented 2016, FDI.

\title{
INFECTION CONTROL CPD FOR DENTAL PROFESSIONALS
}

Vanessa Hoole - Field Sales manager, schülke UK, is delivering infection control training to potentially thousands of dental professionals attending Core CPD Update conferences 2019, organised by Professional Conferences.

The GDC recommends five core areas in which dental professionals should carry out CPD and this series of ten conferences (each one attended by 200-450 delegates) is taking place across the UK. The aim is to ensure the dental team is up to date in core areas, as well as helping satisfy the GDC's requirements for verifiable $\mathrm{CPD}$.

Due to Vanessa's considerable experience in infection prevention, she was asked by Professional Conferences to cover this key area. Vanessa's training entitled 'Delivering excellence ... Preventing risks' encompasses infection control, regulations, legal aspects, microbiology, ethics, staff training and cleaning, disinfection and sterilisation.

For more information on schülke UK, call 0114 254 3500, visit www. schuelke.com or email mail.uk@schuelke. com.

https://www. proconferences.com/ dental-conferences/ 01923859626

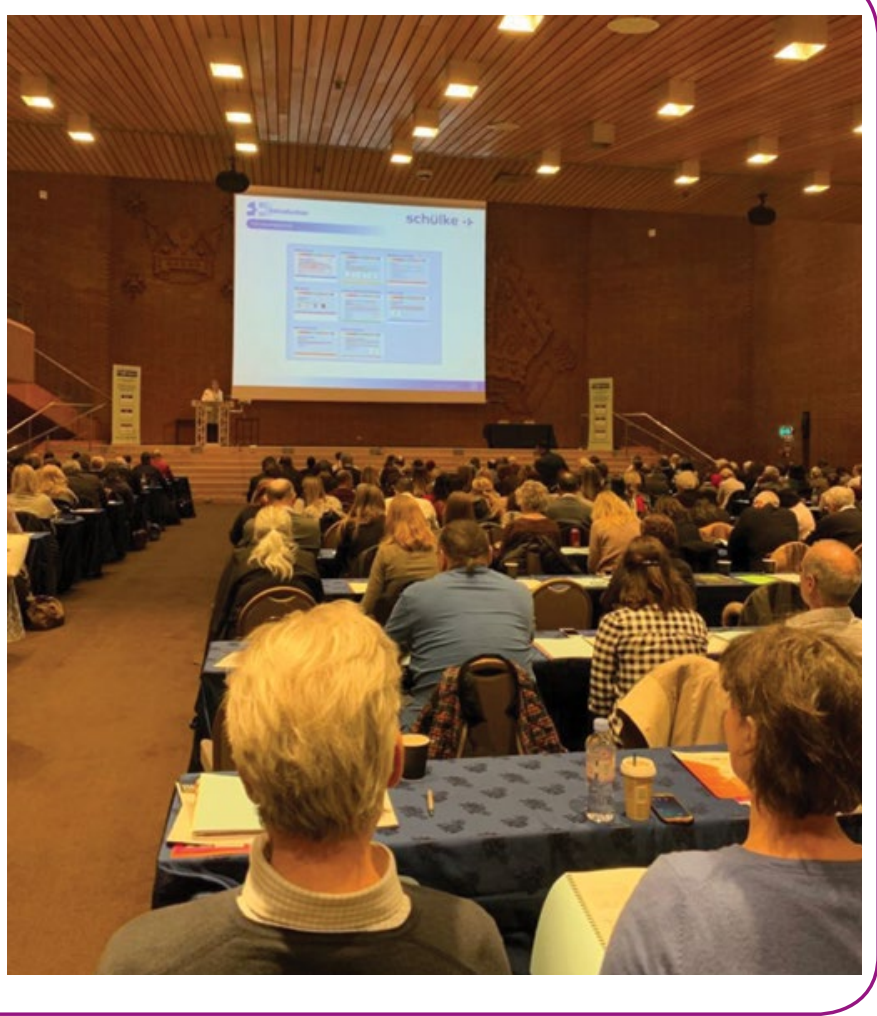

